\title{
Endothelin-1 does not impair insulin-induced angiogenesis in vitro
}

\author{
FABIO PELLEGATTA ${ }^{1}$, CLAUDIA BRAMBILLA ${ }^{1}$, ALICE REDUZZI $^{1}$, MARTA BRAGHERI $^{1}$, \\ GIANPAOLO ZERBINI $^{2}$ and ALBERICO L. CATAPANO ${ }^{1}$
}

\author{
${ }^{1}$ Laboratory of Lipid Metabolism, Department of Pharmacological Sciences, University of Milan; ${ }^{2}$ Renal Pathophysiology \\ Unit, Division of Medicine, Section Nutrition-Metabolism, San Raffaele Scientific Institute, Milan, Italy
}

Received February 21, 2011; Accepted April 8, 2011

DOI: $10.3892 / \mathrm{ijmm} .2011 .689$

\begin{abstract}
Endothelin-1 (ET-1) modulates several vascular functions and plays an important role in the pathogenesis of insulin resistance. However, its role in the pathogenesis of impaired angiogenesis observed under insulin resistance conditions is not known. In the present study, we addressed this issue by analyzing the effect of ET-1 in human umbilical vein endothelial cells (HUVEC) on i) insulin-induced phosphorylation of two protein kinases involved in angiogenesis, Akt and ERK1/2, and on ii) insulin-induced angiogenesis in two in vitro models, those of Matrigel and of fibroblast/endothelial co-culture. Both insulin $(100 \mathrm{ng} / \mathrm{ml})$ and ET-1 (10 nmol/1) dose-dependently increased the phosphorylation of Akt and ERK1/2. Pre-treatment with ET-1 did not suppress the insulin-induced Akt and ERK1/2 phosphorylation. In the two in vitro models of angiogenesis, ET-1 did not inhibit insulin-induced angiogenesis. From these data we conclude that in vitro, at the times and at the concentrations examined, ET-1 does not impair insulininduced angiogenesis.
\end{abstract}

\section{Introduction}

Insulin resistance is a clinical condition characterized by vascular dysfunction and impaired angiogenesis (1-3). The underlying mechanisms that sustain this condition are not completely known. Several alterations in the insulin transduction pathway have been described, and several pathogenetic mechanisms have been proposed (4-6). It has been suggested that endothelin-1 (ET-1) could play a role since its plasma levels are increased in insulin resistance conditions (7-9) and since its increased plasma levels can induce vascular dysfunction (10-12). Furthermore, several studies, performed both in vitro and in vivo, confirmed the role of ET-1 in insulin resistance conditions and vascular dysfunction $(13,14)$.

Correspondence to: Dr Fabio Pellegatta, Laboratory of Lipid Metabolism, Department of Pharmacological Sciences, University of Milan, Via Balzaretti 9, I-20132 Milan, Italy

E-mail: fabio.pellegatta@guest.unimi.it

Key words: insulin, endothelin, angiogenesis, protein kinase, insulin-resistance
Both insulin and ET-1 stimulate angiogenesis through the activation of intracellular kinases, as Akt and ERK1/2 (15-17). However, the transduction pathways of insulin and ET-1 are quite different: insulin activates a tyrosine kinase-coupled receptor (16), whereas ET-1 transduces its signals through a G-protein-coupled receptor $(15,18)$.

It is also known that ET-1 can interfere with insulin transduction at different levels, as for example, through the activation of some isoforms of protein kinase $\mathrm{C}$ that inhibit some early steps of the insulin transduction pathways $(17,19,20)$.

Since the role of ET-1 on the impaired angiogenesis observed in insulin resistance conditions is not known, the aim of the present study was to evaluate the effect of ET-1 on insulin-induced angiogenesis. In this study we demonstrate that at the concentration of $10 \mathrm{nmol} / \mathrm{l}, \mathrm{ET}-1 \mathrm{did}$ not impair insulin-induced angiogenesis evaluated both through the analysis of the levels of phosphorylation of Akt and ERK1/2 and by using Matrigel and fibroblast-endothelial co-culture, two in vitro models of angiogenesis.

\section{Materials and methods}

Isolation, culture and stimulation of endothelial cells. Human umbilical vein endothelial cells (HUVEC) were isolated according to established procedures (21), and cultured under standard conditions in M-199 medium containing 15\% fetal calf serum (FCS), $15 \mathrm{U} / \mathrm{ml}$ heparin (both from Sigma-Aldrich, Milan, Italy) and $20 \mu \mathrm{g} / \mathrm{ml}$ ECGF (Boerhinger Mannheim, Mannheim, Germany) and used within the fifth passage.

After one day of confluence, HUVEC were starved by an overnight incubation in a medium containing $0.5 \%$ of insulinfree bovine serum albumin (BSA) (Sigma). Cells were then washed with phosphate-buffered saline (PBS) $\mathrm{pH} 7.4$ and kept in medium without BSA for a further hour. In the experimental conditions in which the kinase inhibitors were used, they were added $30 \mathrm{~min}$ before the addition of the agonists. The inhibitors used were: $25 \mathrm{ng} / \mathrm{ml}$ rapamycin, $100 \mathrm{nmol} / 1$ wortmannin, $50 \mu \mathrm{mol} / 1 \mathrm{LY} 294002,40 \mu \mathrm{mol} / 1 \mathrm{PD} 98059,5 \mu \mathrm{mol} / 1 \mathrm{UO} 126$, $10 \mu \mathrm{mol} / 1 \mathrm{U} 7,30 \mu \mathrm{mol} / 1 \mathrm{H} 89,1 \mu \mathrm{mol} / 1 \mathrm{Go} 6983,1 \mu \mathrm{mol} / 1$ rottlerin (Calbiochem, La Jolla, CA, USA). According to the experimental design, cells were stimulated with $100 \mathrm{ng} / \mathrm{ml}$ insulin (Sigma) or $10 \mathrm{nmol} / \mathrm{l} \mathrm{ET-1} \mathrm{(Sigma).} \mathrm{In} \mathrm{the} \mathrm{experiments}$ of co-stimulation with ET-1 plus insulin, ET-1 was added 3 min before insulin. After specific times of incubation, cells were washed with PBS and immediately lysed with Laemmli 
buffer at room temperature. Samples were collected, boiled at $95^{\circ} \mathrm{C}$ for 5 min and run on SDS-PAGE gels.

Westernblotting. Samples were run on $12 \%$ SDS-polyacrilamide gel and electrotransferred to a nitrocellulose membrane. Membranes were then blocked for $4 \mathrm{~h}$ at $4^{\circ} \mathrm{C}$ in $5 \%$ dry milk Tris-buffered saline (TBS), washed twice with TBS and incubated overnight at $4^{\circ} \mathrm{C}$ with the primary antibody: antiphospho-Akt (Ser473) (1:1,000) (New England Biolabs Inc., Beverly, MA, USA), anti-Akt (1:1,000, New England Biolabs), anti-ERK, anti-phosphoERK (1:1,000,SantaCruzBiotechnology Inc., Santa Cruz, CA, USA), and anti- $\beta$-actin (1:10,000 Sigma). Blots were then washed four times, incubated with horseradish peroxidase-coniugated secondary antibody for $2 \mathrm{~h}$ at room temperature, washed again and finally incubated with the enhanced chemiluminescence system (ECL, Dupont, Boston, MA, USA).

Matrigel. Growth factor-reduced Matrigel (BD Biosciences, Bedford, MA), a mixture of extracellular and basement membrane proteins derived from the mouse Engelbreth-HolmSwarm sarcoma line was used to induce angiogenesis (22). Matrigel $(100 \mu \mathrm{l})$ was plated in 24-well culture plates, according to the manufacturer's instructions. HUVEC $\left(10^{4}\right.$ cells/plate $)$ were seeded in TC199 medium containing 0.5\% FCS and incubated at $37^{\circ} \mathrm{C}$. According to the experimental design, cells were stimulated with insulin $(100 \mathrm{ng} / \mathrm{ml})$ and/or ET-1 $(10 \mathrm{nmol} / \mathrm{l})$. After 3, 6, 24, 48 and $72 \mathrm{~h}$ the length of the tube-like structures delimiting lacunae were analyzed. The length of the tube-like structures (expressed as $\mathrm{mm} /$ field) and the number of cells (expressed as number of cells/field) present between the rings, were quantitatively evaluated by using an image analysis software (Scion Image) (NIH Image 5.2) in randomly selected high-power fields (x40).

Fibroblast-endothelium co-culture. The effect of insulin and/or ET-1 on angiogenesis was also evaluated by analyzing the capillary formation in co-cultures of HUVEC and human fibroblasts (primary cells) of dermal origin (23). VEGF (10 ng/ml) was used as a positive control. Briefly, $25 \times 10^{3}$ HUVEC or human fibroblasts/plate were seeded into a 24-well culture plate in EBM-2 culture medium (Clonetics, San Diego, CA) and the medium was changed on Day 4, 7 and 11. Where needed, $100 \mathrm{ng} / \mathrm{ml}$ insulin and/or $10 \mathrm{nmol} / \mathrm{l}$ ET-1 were added at every medium change. After 14 days of culture, plates were fixed and endothelial cells were immunohistochemically stained. Briefly, plates were washed with PBS, fixed in $70 \%$ ethanol for $30 \mathrm{~min}$, blocked with horse serum for $30 \mathrm{~min}$, stained with $10 \mu \mathrm{g} / \mathrm{ml}$ anti-CD31 (clone M89D3, kind gift of Dr M. Zocchi) for $1 \mathrm{~h}$ at room temperature, followed by incubation with the avidin/streptavidin-coniugated secondary antibody. Positive cells were detected using the Vector Staining kit (Vector Laboratories Inc., Burlingame, CA). The length of the capillary-like structures (expressed as $\mathrm{mm}$ /field) was measured using the Scion Image image analysis software (NIH Image 5.2).

Statistical analysis. Statistical analysis was performed with the Mann-Whitney and Wilcoxon tests. The results were considered significant at $\mathrm{P}<0.05$.

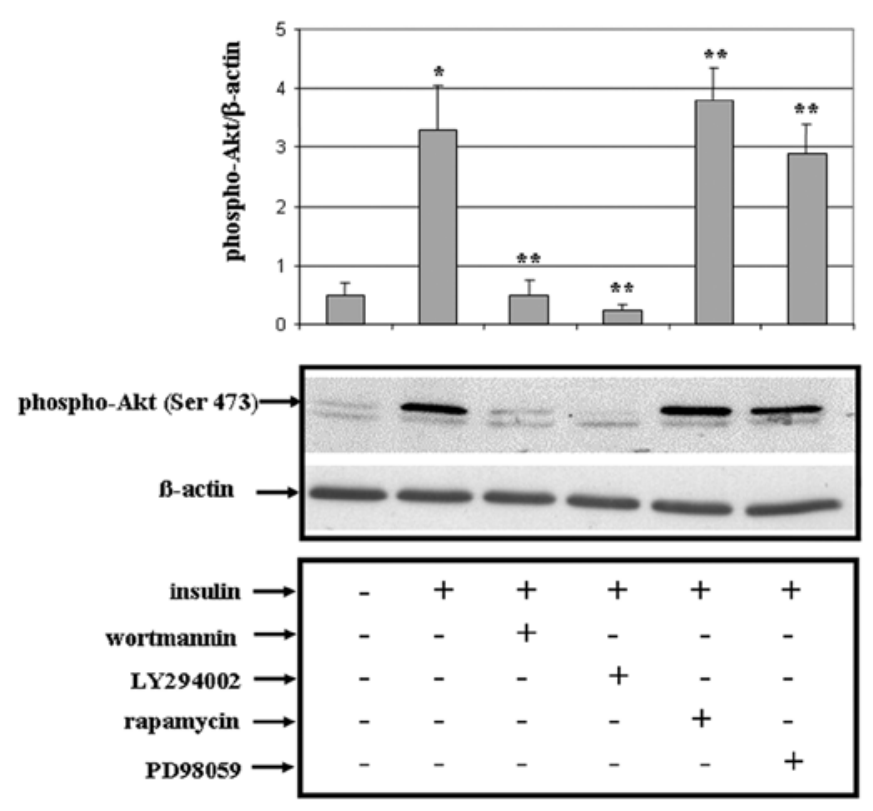

Figure 1. Effect of protein kinase inhibitors on Akt phosphorylation induced by insulin. Thirty minutes before insulin stimulation $(100 \mathrm{ng} / \mathrm{ml})$, cells were treated with $100 \mathrm{nmol} / 1$ wortmannin (PI-3K inhibitor), $50 \mu \mathrm{mol} / 1 \mathrm{LY} 294002$ (PI-3K inhibitor), $25 \mathrm{ng} / \mathrm{ml}$ rapamycin (mTOR inhibitor) or $40 \mu \mathrm{mol} / 1$ PD98059 (MEK inhibitor) according to the experimental design. After 30 min of stimulation cells were lysed and run on SDS-PAGE gels. The gels are representative of one of three replicate experiments, whereas the analysis is performed from the data derived from the three experiments. ${ }^{*} \mathrm{P}<0.05$ vs. control; ${ }^{* *} \mathrm{P}<0.05$ vs. insulin alone.

\section{Results}

The aim of this study was to investigate the role of ET-1 in the modulation of insulin-induced angiogenesis in order to evaluate its possible role in the pathogenesis of the impaired angiogenesis observed under insulin resistance conditions. We addressed this issue in two ways: i) by analyzing the level of phosphorylation/activation of Akt and ERK1/2, two protein kinases involved in angiogenesis $(24,25)$, in HUVEC, and ii) by using Matrigel and fibroblast-endothelium co-culture, two in vitro models of angiogenesis.

Effects of insulin and ET-1 on Akt and ERK1/2 phosphorylation in HUVEC. Akt and ERK1/2 belong to the PI-3K/Akt/mTOR and MEK/MAPK/ERK1/2 pathways, respectively, and their activity is modulated by a site-specific phosphorylation. We have therefore, evaluated by Western blotting their levels of phosphorylation as an index of their activation.

As known (26), in HUVEC, $100 \mathrm{ng} / \mathrm{ml}$ insulin increases the phosphorylation of both Akt and ERK1/2 as early as at 5 min after treatment with further increases in the following 15 and 30 min (data not shown). Insulin-induced Akt phosphorylation appears to be PI-3K dependent as it was totally inhibited by wortmannin and LY294002; and partially MEK/ MAPK-dependent since PD98059 (a MEK inhibitor) reduced Akt phosphorylation by $20 \pm 5 \%$, whereas a modest increase $(10 \pm 4.5 \%)$ was observed with rapamycin (an inhibitor of the mammalian Target of rapamycin, mTOR) (Fig. 1). The phosphorylation of Akt was also inhibited by rottlerin (a PKC $\delta$ inhibitor) and $\mathrm{H} 89$ (РKC $\mu$ inhibitor) whereas Go6983 (a PKC $\alpha$ and $\beta$ inhibitor) had no effect (Fig. 2). 

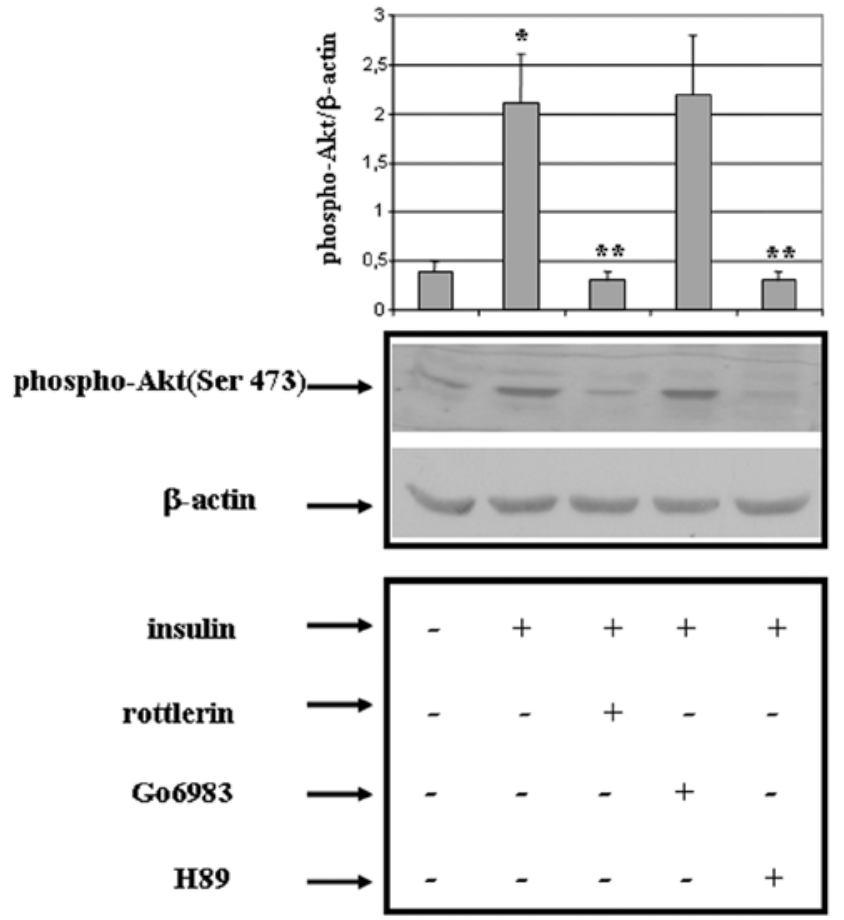

Figure 2. Effect of protein kinase inhibitors on Akt phosphorylation induced by insulin. Thirty minutes before insulin stimulation $(100 \mathrm{ng} / \mathrm{ml})$, cells were treated with $1 \mu \mathrm{mol} / 1$ rottlerin (PKC $\delta$ inhibitor), $1 \mu \mathrm{mol} / 1$ Go6983 (PKC $\alpha / \beta$ inhibitor), $30 \mu \mathrm{mol} / 1 \mathrm{H} 89$ ( $\mathrm{PKC} \mu$ inhibitor) according to the experimental design. After $30 \mathrm{~min}$ of stimulation cells were lysed and run on SDS-PAGE gels. The gels are representative of one of three replicate experiments, whereas the analysis was performed from the data derived from the three experiments. ${ }^{*} \mathrm{P}<0.05$ vs. control; ${ }^{* *} \mathrm{P}<0.05$ vs. insulin alone.
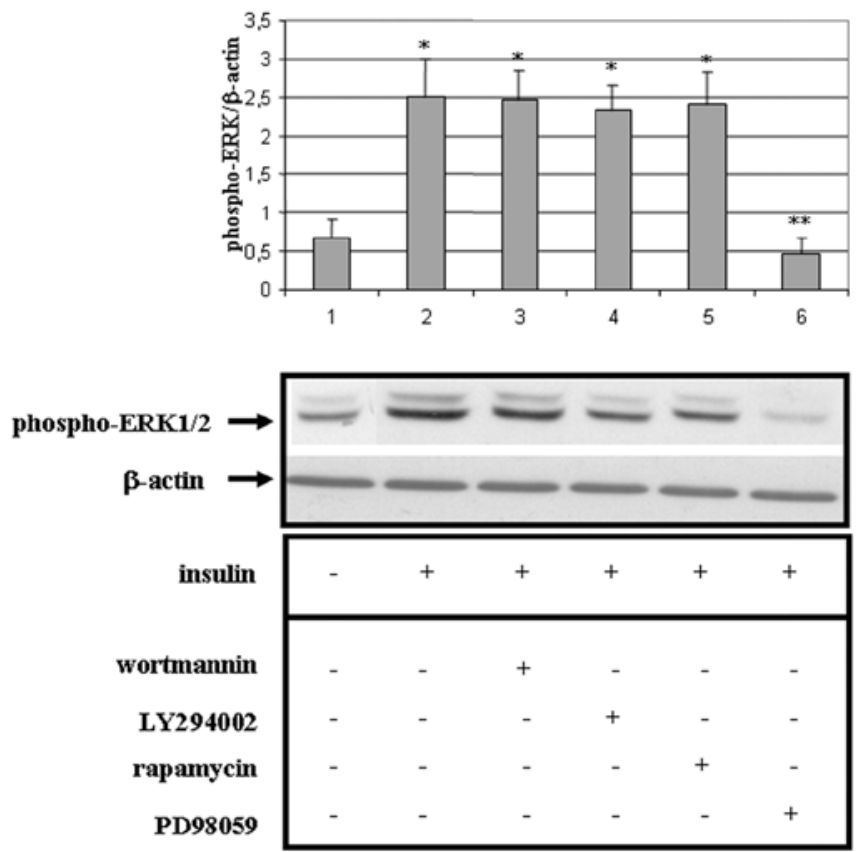

Figure 3. Effect of protein kinase inhibitors on ERK1/2 phosphorylation induced by insulin. Thirty minutes before insulin stimulation $(100 \mathrm{ng} / \mathrm{ml})$, cells were treated with $100 \mathrm{nmol} / 1$ wortmannin (PI-3K inhibitor), $50 \mu \mathrm{mol} / 1$ LY294002 (PI-3K inhibitor), $25 \mathrm{ng} / \mathrm{ml}$ rapamycin (mTOR inhibitor) or $40 \mu \mathrm{mol} / 1$ PD98059 (MEK inhibitor) according to the experimental design. After 30 min of stimulation cells were lysed and run on SDS-PAGE gels. The gels are representative of one of three replicate experiments, whereas the analysis is performed from the data derived from the three experiments. ${ }^{*} \mathrm{P}<0.05$ vs. control; ${ }^{* *} \mathrm{P}<0.05$ vs. insulin alone). a
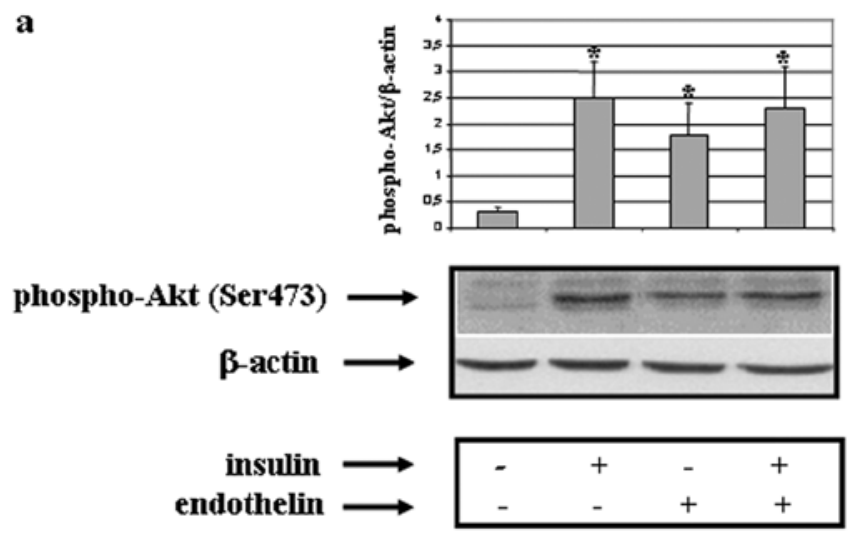

b

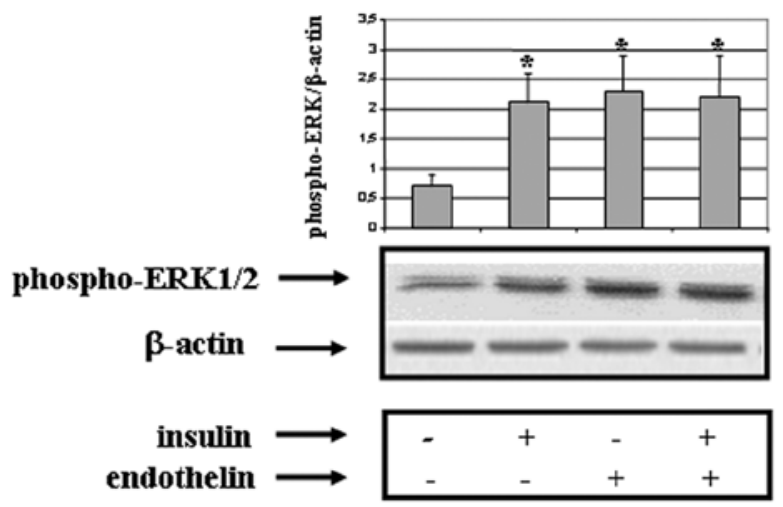

Figure 4. Effect of endothelin-1 $(10 \mathrm{nmol} / \mathrm{l})$ on Akt and ERK1/2 phosphorylation induced by insulin. Three minutes before insulin stimulation $(100 \mathrm{ng} / \mathrm{ml})$, cells were stimulated with $10 \mathrm{nmol} / 1$ endothelin- 1 , according to the experimental design. After $30 \mathrm{~min}$ of stimulation cells were lysed and run on SDS-PAGE gels. The gels are representative of one of three replicate experiments, whereas the analysis was performed from the data derived from the three experiments. ${ }^{*} \mathrm{P}<0.05$ vs. control.

Insulin-induced ERK1/2 phosphorylation was totally inhibited by PD98059 (and UO126, data not shown), whereas wortmannin, LY294002 and rapamycin had no significant effect (Fig. 3).

In preliminary experiments we have examined the ability of different concentrations of ET-1 (5, 10, 50 and $100 \mathrm{nmol} / \mathrm{l})$ to stimulate Akt and ERK-1/2 phosphorylation. According to the observations that: i) ET-1 at $10 \mathrm{nM}$ was able to increase these phosphorylations by 2-5-fold, ii) greater concentrations of ET-1 only modestly further increased these phosphorylations (data not shown), and iii) concentrations of ET-1 $>10 \mathrm{nM}$ are not present in vivo in insulin resistance conditions $(8,9,11-13)$, we chose to use the ET-1 dose of $10 \mathrm{nmol} / \mathrm{l}$ in our experiments.

The $10 \mathrm{nmol} / \mathrm{l}$ concentration of ET-1 increased the level of Akt and ERK1/2 phosphorylation as early as at $5 \mathrm{~min}$, and this effect persisted until $60 \mathrm{~min}$. The Akt phosphorylation was totally inhibited by LY294002, whereas rapamycin and PD89059 induced a modest increase. ERK1/2 phosphorylation was inhibited by PD98059 and by U0126 but was unaffected by LY294002 and rapamycin (data not shown).

We then evaluated the effect of ET-1 on insulin-induced Akt and ERK1/2 phosphorylation. ET-1 (10 nmol/l) added $3 \mathrm{~min}$ before insulin stimulation, did not modify the level of Akt and ERK1/2 phosphorylation as compared to that observed with insulin alone (Fig. 4). The addition of LY294002, rottlerin 

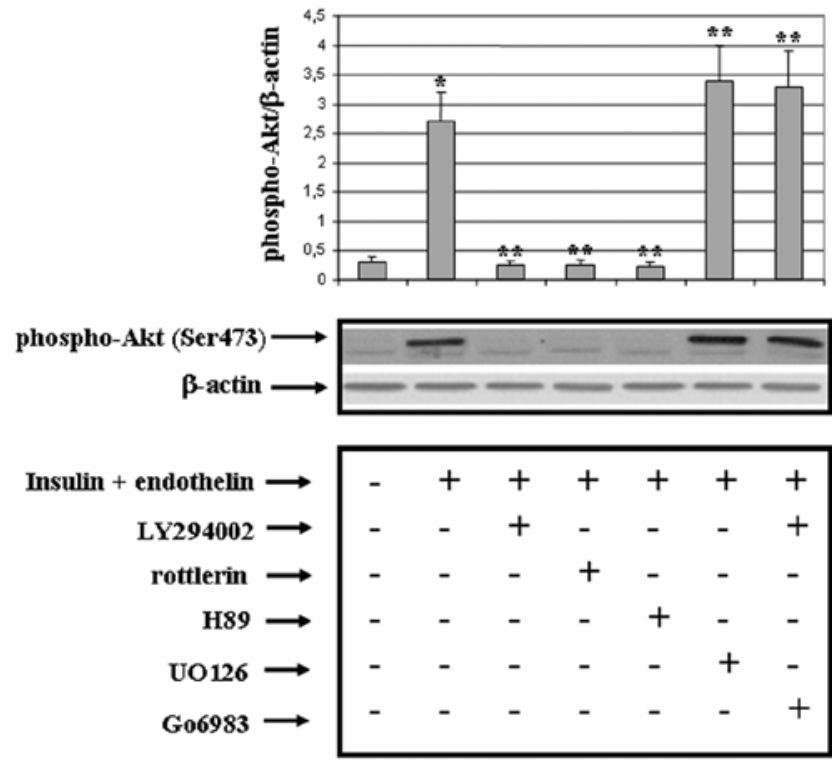

Figure 5. Effect of protein kinase inhibitors on Akt phosphorylation induced by endothelin-1 $(10 \mathrm{nmol} / \mathrm{l})$ plus insulin $(100 \mathrm{ng} / \mathrm{ml})$. Thirty minutes before endothelin-1 plus insulin stimulation $(10 \mathrm{nmol} / \mathrm{l})$, cells were treated with $50 \mu \mathrm{mol} / 1 \mathrm{LY} 294002$ (PI-3K inhibitor), $1 \mu \mathrm{mol} / 1$ rottlerin (PKCס inhibitor), $30 \mu \mathrm{mol} / 1 \mathrm{H} 89$ ( $\mathrm{PKC} \mu$ inhibitor), $5 \mu \mathrm{mol} / 1 \mathrm{UO} 126$ (MEK inhibitor) or $1 \mu \mathrm{mol} / 1 \mathrm{Go} 6983$ (PKC $\alpha / \beta$ inhibitor) according to the experimental design. After 30 min of stimulation cells were lysed and run on SDS-PAGE gels. The gels are representative of one of three replicate experiments, whereas the analysis is performed from the data derived from the three experiments. ${ }^{*} \mathrm{P}<0.05$ vs. control; ${ }^{* *} \mathrm{P}<0.05$ vs. insulin+endothelin- 1 alone.

and H89 totally inhibited Akt phosphorylation, whereas UO126 and Go6983 increased it by $44 \pm 22 \%$ and $40 \pm 25 \%$, respectively (Fig. 5). The level of ERK1/2 phosphorylation was reduced by PD98059 and Go6983, but was unaffected by LY294002, rottlerin and H89 (data not shown).

Effects of insulin and ET-1 on the Matrigel model of in vitro angiogenesis. A further aim of our study was to analyze the effect of ET-1 on insulin-induced angiogenesis in Matrigel and fibroblast-endothelial co-culture, two models of in vitro angiogenesis.

In the Matrigel model, within only a few hours from seeding, endothelial cells grew and formed tube-like structures delimiting lacunae. The length of these tube-like structures is considered to reflect the level of angiogenesis present in the conditions examined.

In this model, both insulin and ET-1 increased the length of these tube-like structures as compared to the control $(24.3 \pm 2.51$ and $23.6 \pm 3.05$ vs. $10.66 \pm 2.51$, respectively). The appearance of the rings was delayed in respect to that observed with VEGF (10 ng/ml) (data not shown), but they persisted longer. Another feature observed after stimulation with insulin or ET-1 was the presence, between the rings, of many proliferating cells $(145.6 \pm 7.3,142.6 \pm 5.03)$ compared to the control (97.6 \pm 2.5$)$. Stimulation with insulin plus ET-1 did not modify the length of the tube-like structures $(24.6 \pm 2.5)$ and the number of the proliferating cells (144.6 \pm 7.3$)$ compared to that observed with insulin or ET-1 alone. (Fig. 6).

Effects of insulin and ET-1 on the fibroblast-endothelium co-culture model of in vitro angiogenesis. In the angiogenesis
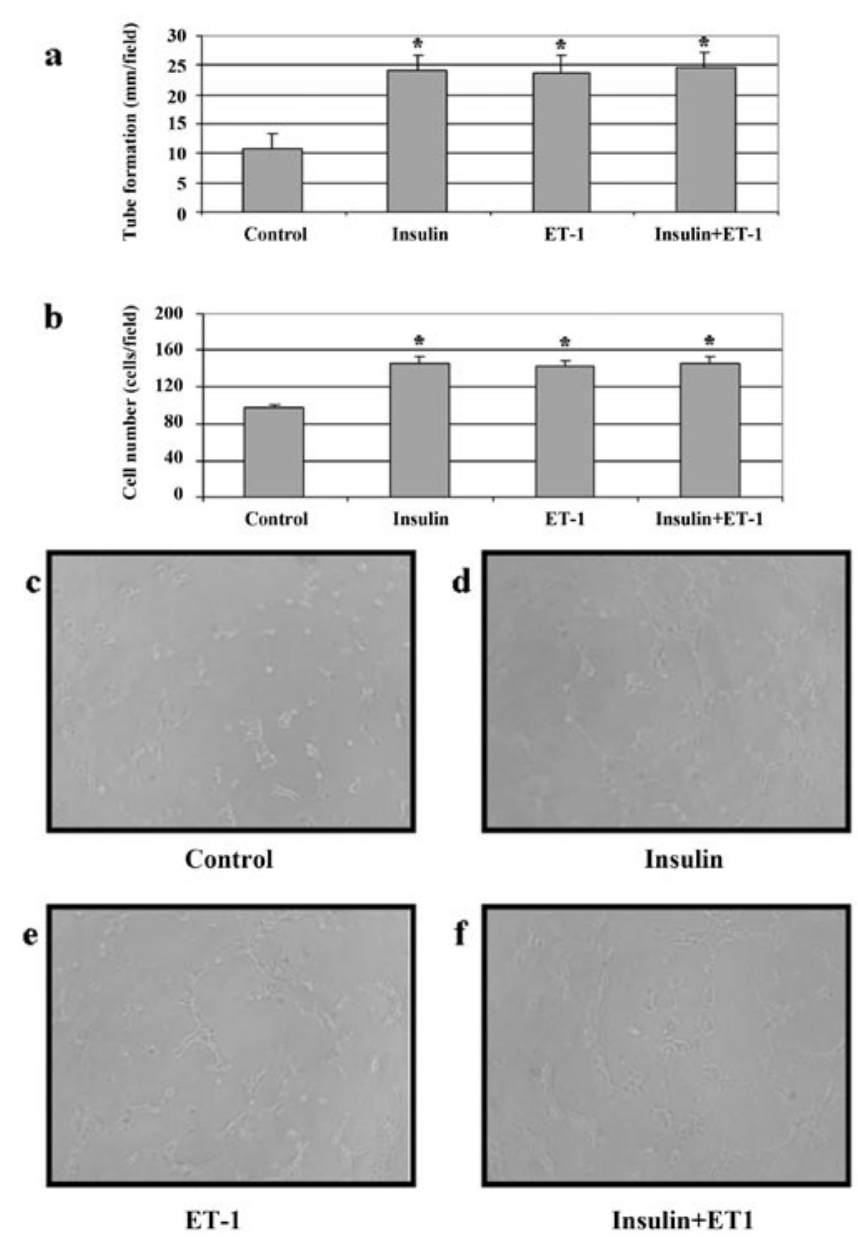

Figure 6. Effect of insulin and/or endothelin-1 (ET-1) on in vitro angiogenesis evaluated with the Matrigel model. HUVEC were seed on plates coated with Matrigel; according with the experimental design, cell were: not treated (c); treated with insulin $100 \mathrm{ng} / \mathrm{ml}(\mathrm{d})$, treated with $10 \mathrm{nmol} / 1 \mathrm{ET}-1$ (e); treated with $10 \mathrm{nmol} / \mathrm{l} \mathrm{ET-1}+100 \mathrm{ng} / \mathrm{ml}$ insulin (f). After $24 \mathrm{~h}$ the length of the tube-like structure (a) and the number of cells present in every field (b) were measured and compared. The images (c-f) are representative of one of three experiments performed in triplicate. ${ }^{*} \mathrm{P}<0.05$ vs. control.

model of fibroblast-endothelium co-culture, after 14 days of culture, endothelial cells form thin prolongations between the fibroblasts whose length is considered to reflect the level of the angiogenesis present.

The addition of insulin or ET-1 to the culture medium increased the length of these vascular-like structures $(48.3 \pm 4.5$ and 50.6 \pm 4.1 , respectively, compared to $31 \pm 3$ in the control). The co-stimulation with insulin and ET-1 did not modify the length of these vascular-like structures (48.6 \pm 4.04$)$ (Fig. 7).

\section{Discussion}

In the industrialized societies the clinical relevance of the insulin resistance conditions is increasing. Indeed, the clinical complications, a direct consequence of the accelerated atherosclerosis present in these syndromes, are responsible for the impaired quality of life observed in these patients (27). For these reasons, a great effort has been devoted to the understanding of the molecular basis of insulin resistance.

Insulin resistance conditions are characterized by an impairment, observed at several levels of the insulin transduction 

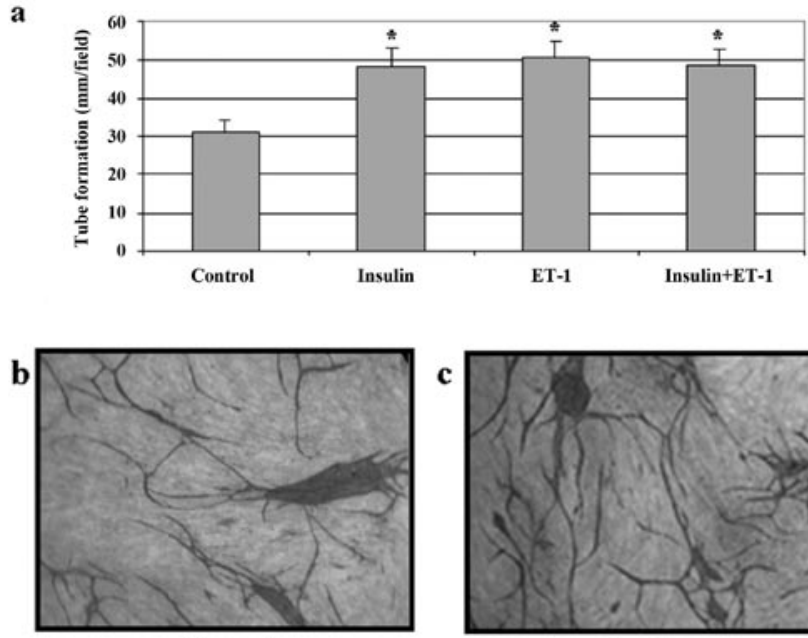

Control

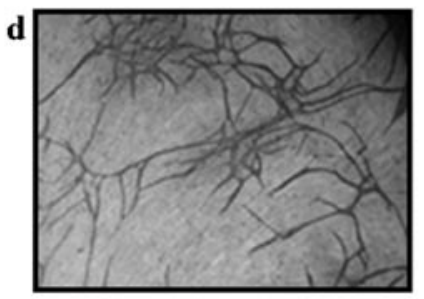

ET-1

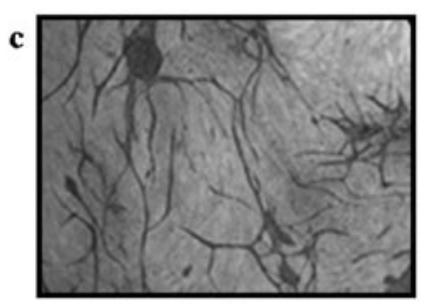

Insulin

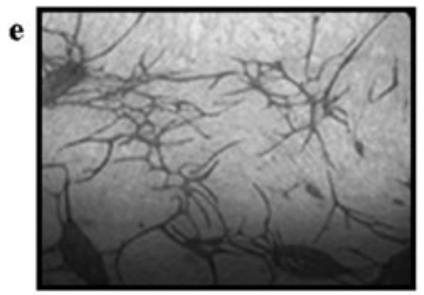

Insulin+ET1

Figure 7. Effect of insulin and/or endothelin-1 (ET-1) on in vitro angiogenesis evaluated with the fibroblast-endothelium co-culture model. HUVEC and fibroblasts were seeded together on plates. According with the experimental design, cell were: not treated (b); treated with $100 \mathrm{ng} / \mathrm{ml}$ insulin (c); treated with $10 \mathrm{nmol} / 1$ ET-1 (d); treated with ET-1 $10 \mathrm{nmol} / 1$ + insulin $100 \mathrm{ng} / \mathrm{ml}$ (e) After 14 days, the length of the vascular-like structures (endothelial microtubules) were counted and compared (a). The images (b-e) are representative of one of three experiments performed in triplicate. ${ }^{*} \mathrm{P}<0.05$ vs. control.

pathway. Reduced PI-3K, Akt and eNOS activity, reduced intracellular and membrane bound PIP2 levels as well as reduced actin-dependent GLUT4 translocation have been described (3-6).

Although insulin resistance is a syndrome with a multifactorial origin (28), a role of circulating/humoral factors, and among these ET-1, has been demonstrated. Insulin resistance conditions are, indeed, frequently characterized by an increase of ET-1 plasma levels $(8,9)$, and in vitro studies have demonstrated that ET-1 inhibits some intracellular steps of the insulin transduction pathway (7) and that high plasma levels of ET-1 are able to induce vascular dysfunction (11). A microand macro-angiopathy, as well as an impaired collateral vessel formation, are observed in the insulin resistance syndromes (14), but the role of ET-1 in this impaired angiogenesis is not known.

Individually taken, both insulin and ET-1 are important inducers of angiogenesis $(15,16,18)$. The importance of ET-1 in the angiogenesis is further confirmed by its increased expression in the tissues where angiogenesis is present, such as in the tumors (29). On the other hand, since ET-1 is known to inhibit some steps of insulin transduction, it is conceivable that it may have an inhibitory role in insulin-induced angiogenesis.

To address this issue, in the present study we have analyzed the effect of ET-1 on insulin-induced angiogenesis by assessing the activation of Akt and ERK, two protein kinases involved in angiogenesis, and by using two in vitro models of angiogenesis. At the concentration of $10 \mathrm{nmol} / \mathrm{l}$, ET-1 did not impair insulin-induced Akt and ERK activation, or the insulininduced angiogenesis in two in vitro models of angiogenesis.

Although under our experimental conditions we did not observe an inhibitory effect of ET-1 on insulin-induced angiogenesis, the observation that in conditions of co-stimulation with insulin and ET-1 the use of inhibitors of MEK/MAPK or of PKC $\alpha / \beta$ induced an increased phosphorylation of $\mathrm{Akt}$, suggest that ET-1 stimulates PKC $\alpha / \beta$ and MEK/MAPK that in turn partially inhibit Akt. This suggests that a small level of inhibition is present. On the other hand, recent studies have demonstrated that ET-1 can induce insulin resistance by reducing PIP2 production without modifying the activation of some isoforms of Akt (30). Therefore, our data do not rule out that other insulin-induced pathways could be inhibited by ET-1 and that other experimental conditions may lead to a more clear inhibition of insulin-induced angiogenesis. For example, the addition of phorbol ester to cells stimulated with ET-1 and insulin induces a strong inhibition of Akt (data not shown). This suggests that a greater level of stimulation of the diacylglycerol-dependent PKC, could confer a significant level of inhibition. However, the concentration of ET-1 (10 nmol/l) used in our experiments already corresponds to higher plasma concentrations $(>10 \mathrm{pg} / \mathrm{ml})$ that can be observed in insulin resistance conditions, and higher concentrations would be above the physiological and pathological levels $(7-9,11,12)$.

In our study we confirmed the ability of insulin to activate Akt and ERK1/2 in human endothelial cells, and that such activations are PI-3K- and MEK/MAPK-dependent, respectively.

The present study demonstrates that ET-1 activates Akt in HUVEC. It is known that ET-1 does not activate Akt through the classical pathway activated by tyrosine receptors. The binding of ET-1 to its G-protein-coupled receptor, induces the activation of PI-3K through the binding of the G-protein $\beta \gamma$ subunits with its catalytic domain (18) that, in turn, induces the activation of the downstream kinases. Accordingly, in our study Akt is activated by ET-1 via a PI-3K pathway. The fact that PD89059 and UO126 induced an increase in Akt phosphorylation after ET-1 stimulation indicates the existence of an inhibitory action of MEK/MAPK on Akt.

Several isoforms of protein kinase $\mathrm{C}$ are known to modulate insulin transduction. In particular, isoforms $\alpha$ and $\beta$ exert an inhibitory action, whereas $\mathrm{PKC} \delta, \varepsilon$ and $\mu$ are activators. Our data are in agreement with such roles: insulin-induced Akt phosphorylation was reduced by rottlerin (a PKC $\delta$ inhibitor) and by $\mathrm{H} 89$ (a PKC $\mu$ inhibitor). The inhibition of the $\alpha$ and $\beta$ isoforms of PKC by Go6983 did not modify the phosphorylation of Akt induced by insulin, indicating that insulin does not stimulate these inhibitory kinases. A different effect was observed when ET-1 was added to insulin. In this case, indeed, the inhibition of the PKC $\alpha$ and $\beta$ increased the level of Akt phosphorylation, (as also observed with the inhibition of the downstream kinase MEK/MAPK).

In our study we confirmed that insulin activates ERK1/2 in a MEK-dependent fashion. We show that ERK1/2 phosphorylation 
increased after PI-3K and mTOR inhibition, indicating an inhibitory role of these kinases on ERK1/2 phosphorylation.

Also, by using the two models of in vitro angiogenesis we observed that ET-1 at $10 \mathrm{nmol} / \mathrm{l}$ does not impair insulininduced angiogenesis. We also confirmed that, given alone, both insulin and ET-1 increase angiogenesis. An interesting observation in the Matrigel model is that after insulin and/or ET-1 stimulation, a great number of cells was present in the wall of the angiogenic rings compared to that observed in the control sample. This effect could be explained by the increased ERK1/2 activation induced by these agonists that is known to sustain the proliferation process (31).

In conclusion, in our experimental conditions, ET-1 at the doses and at the times used, does not impair insulin-induced angiogenesis.

\section{Acknowledgements}

The present study was supported by the grant F.I.R.B (RBNE01HLAK_006) to A.L.C. The sponsor of the study had no role in the study design, data collection, data analysis, data interpretation or preparation of the manuscript.

\section{References}

1. Abaci A, Ozuzhan A, Kahraman S, Eryol NK, Unal S, Arinç H and Ergin A: Effect of diabetes mellitus on formation of coronary collateral vessels. Circulation 99: 2239-2242, 1999.

2. Busija DW, Miller AW, Katakam P, Simandle S and Erdos B: Mechanisms of vascular dysfunction in insulin resistance. Curr Opin Investig Drugs 5: 929-935, 2004.

3. Steinberg HO and Baron AD: Vascular function, insulin resistance and fatty acids. Diabetologia 45: 623-634, 2002.

4. Brozinick JT Jr, Roberts BR and Dohm GL: Defective signaling through Akt-2 and -3 but not Akt-1 in insulin-resistant human skeletal muscle: potential role in insulin resistance. Diabetes 52 : 935-941, 2003.

5. Brozinick JT Jr, Hawkins ED, Strawbridge AB and Elmendorf JS: Disruption of cortical actin in skeletal muscle demonstrates an essential role of the cytoskeleton in glucose transporter 4 translocation in insulin-sensitive tissues. J Biol Chem 279: 40699-40706, 2004.

6. Chen G, Raman P, Bhonagiri P, Strawbridge AB, Pattar GR and Elmendorf JS: Protective effect of phosphatidylinositol 4,5-bisphosphate against cortical filamentous actin loss and insulin resistance induced by sustained exposure of 3T3-L1 adipocytes to insulin. J Biol Chem 279: 39705-39709, 2004.

7. Jiang ZY, Zhou QL, Chatterjee A, Feener EP, Myers MG Jr, White MF and King GL: Endothelin-1 modulates insulin signaling through phosphatidylinositol 3-kinase pathway in vascular smooth muscle cells. Diabetes 48: 1120-1130, 1999.

8. Piatti PM, Monti LD, Galli L, Fragasso G, Valsecchi G, Conti M, Gernone F and Pontiroli AE: Relationship between endothelin-1 concentration and metabolic alterations typical of the insulin resistance syndrome. Metabolism 49: 748-752, 2000.

9. Takahashi K, Ghatei MA, Lam HC, O'Halloran DJ and Bloom SR: Elevated plasma endothelin in patients with diabetes mellitus. Diabetologia 33: 306-310, 1990.

10. Amiri F, Virdis A, Neves MF, Iglarz M, Seidah NG, Touyz RM, Reudelhuber TL and Schiffrin EL: Endothelium-restricted over expression of human endothelin-1 causes vascular remodeling and endothelial dysfunction. Circulation 110: 2233-2240: 2004.
11. Wilkes JJ, Hevener A and Olefsky J: Chronic endothelin-1 treatment leads to insulin resistance in vivo. Diabetes 52: 1904-1909, 2004.

12. Juan CC, Fang VS, Huang YJ, Kwok CF, Hsu YP and Ho LT: Endothelin-1 induces insulin resistance in conscious rats. Biochem Biophys Res Commun 227: 694-699, 1996.

13. Jiang ZY, He Z, King BL, Kuroki T, Opland DM, Suzuma K, Suzuma I, Ueki K, Kulkarni RN, Kahn CR and King GL: Characterization of multiple signaling pathways of insulin in the regulation of vascular endothelial growth factor expression in vascular cells and angiogenesis. J Biol Chem 278: 31964-31971, 2003.

14. Salani D, Taraboletti G, Rosano L, Di Castro V, Borsotti P, Gavazzi R and Bagnato A: Endothelin-1 induces an angiogenic phenotype in cultured endothelial cells and stimulates neovascularization in vivo. Am J Pathol 157: 1703-1711, 1999.

15. Liu S, Premont RT, Kontos CD, Huang J and Rockey DC: Endothelin-1 activates endothelial cell nitric-oxide synthase via heterotrimeric G-protein $\beta \gamma$ subunit signaling to protein kinase B/Akt. J Biol Chem 278: 49929-49935, 2003.

16. Lizcano JM and Alessi DR: The insulin signalling pathway. Curr Biol 12: R236-R238, 2002.

17. Chou YC, Perng JC and Juan CC: Endothelin-1 inhibits insulinstimulated glucose uptake in isolated rat adipocytes. Biochem Biophys Res Commun 202: 688-693, 1994.

18. Sugden PH: An overview of endothelin signaling in the cardiac myocyte. J Mol Cell Cardiol 35: 871-886, 2003.

19. Korzick DH, Muller-Delp JM and Dougherty P: Exaggerated coronary vasoreactivity to endothelin-1 in aged rats: role of protein kinase C. Cardiovasc Res 66: 384-392, 2005.

20. Schiffrin EL: Role of endothelin-1 in hypertension and vascular disease. Am J Hypertens 14: S83-S89, 2001.

21. Jaffe EA, Nachman RL and Becker CG: Culture of human endothelial cells derived from umbilical veins. Identification by morphologic and immunologic criteria. J Clin Invest 52: 2745-2756, 1973.

22. Ponce ML: Tube formation: an in vitro matrigel angiogenesis assay. Methods Mol Biol 467: 183-188, 2009.

23. Saito M, Hamasaki M and Shibuja M: Induction of tube formation by angiopoietine-1 in endothelial cell/fibroblast co-culture is dependent on endogenous VEGF. Cancer Sci 94: 782-790, 2003.

24. Shiojima I and Walsh K: Role of Akt signaling in vascular homeostasis and angiogenesis. Circ Res 90: 1243-1250, 2002.

25. Wang Y, Wei X and Xiao X: Arachidonic acid epoxygenase metabolites stimulate endothelial cell growth and angiogenesis via mitogen-activated protein kinase and phosphatidylinositol 3-kinase/Akt signaling pathways. J Pharmacol Exp Ther 314: 522-532, 2005.

26. Pellegatta F, Catapano AL, Luzi L and Terruzzi L: In human endothelial cells amino acids inhibit insulin-induced Akt and ERK1/2 phosphorylation by an mTOR-dependent mechanism. J Cardiovasc Pharmacol 47: 643-649, 2006.

27. Chan JC, Tong PC and Critchley JA: The insulin resistance syndrome: mechanisms of clustering of cardiovascular risk. Semin Vasc Med 2: 45-57, 2002.

28. LeRoith D: Beta-cell dysfunction and insulin resistance in type 2 diabetes: role of a metabolic and genetic abnormalities. Am J Med 113 (Suppl 6A): 3S-11S, 2002.

29. Salani D, Taraboletti G and Rosano L: Endothelin-1 induces tumor proteinase activation and invasiveness of ovarian carcinoma cells. Cancer Res 61: 8340-8346, 2001.

30. Strawbridge AB and Elmendorf JS: Phosphatidylinositol 4,5-bisphosphate reverses endothelin-1-induced insulin resistance via an actin-dependent mechanism. Diabetes 54: 1698-1705, 2005.

31. Wong C and Jin ZG: Protein kinase C-dependent protein kinase D activation modulates ERK signal pathway and endothelial cell proliferation by vascular endothelial growth factor. J Biol Chem 280: 33262-33269, 2005. 